\title{
Prominent role of RAB39A-RXRB axis in cancer development and stemness
}

\author{
Tokuhiro Chano ${ }^{1}$, Hiroko Kita ${ }^{1}$, Sofia Avnet ${ }^{2}$, Silvia Lemma ${ }^{2}$ and Nicola Baldini ${ }^{2,3}$ \\ ${ }^{1}$ Department of Clinical Laboratory Medicine, Shiga University of Medical Science, Otsu, Shiga, Japan \\ ${ }^{2}$ Orthopaedic Pathophysiology and Regenerative Medicine Unit, Istituto Ortopedico Rizzoli, Bologna, Italy \\ ${ }^{3}$ Department of Biomedical and Neuromotor Sciences, University of Bologna, Bologna, Italy \\ Correspondence to: Tokuhiro Chano, email: chano@belle.shiga-med.ac.jp
}

Keywords: $R A B 39 A$; RXRB; cancer stem cell; spherogenicity; tumorigenesis

Received: September 19, 2017 Accepted: November 16, $2017 \quad$ Published: January 04,2018

Copyright: Chano et al. This is an open-access article distributed under the terms of the Creative Commons Attribution License 3.0 (CC BY 3.0), which permits unrestricted use, distribution, and reproduction in any medium, provided the original author and source are credited.

\section{ABSTRACT}

In this study, we found that RAB39A, a member of the RAS oncogene family, was selectively expressed in cancer cells of different histotypes, by analyzing gene expression in human osteosarcoma cells and the cancer stem cells (CSCs) and by comparing them with normal cells through global transcriptomics and principal component analyses. We further validated $R A B 39 A$ as a therapeutic target, by silencing its expression. The silencing impaired cancer stemness and spherogenic ability in vitro, as well as tumorigenesis in vivo. RNA-seq analyses in the silenced spheres suggested that RAB39A is associated downstream with RXRB and KLF4. Notably, $R X R B$ expression was inhibited in RAB39A-silenced CSCs. Induced overexpression of $R X R B$ in $R A B 39 A$-silenced cells restored spherogenic ability and tumorigenesis, confirming RXRB as a major effector of RAB39A. Quantitative RT-PCR analysis of $\sim 400$ human cancer tissues showed that RAB39A was highly expressed in sarcomas and in malignancies of lymphoid, adrenal and testicular tissues. Our data provide the rationale for targeting of the RAB39A-RXRB axis as a therapy for aggressive cancers.

\section{INTRODUCTION}

Cancers develop in a variety of microenvironmental conditions and under the selective pressure of hostile conditions, such as low extracellular $\mathrm{pH}$, low oxygen levels, and low metabolite concentrations [1]. Such hostile microenvironments influence tumor growth, progression, invasiveness, immune escape, and drug resistance [2, 3]. Studies aimed at identifying anticancer molecules need to take into account the tumor microenvironment and its features. An important aspect of the tumor microenvironment is cancer-associated extracellular acidosis, which is a general phenomenon mainly derived from the metabolic switch to persistent aerobic glycolysis, even under adequate oxygen conditions, the so called "Warburg effect" [4]. Acidosis plays a critical role in the progression of many cancers as it fosters chemo- and radioresistance, neo-angiogenesis, invasion and stemness [5]. On this basis, we used various "-omics" approaches to identify specific and reliable anticancer therapeutic targets $[3,6,7]$ by comparing gene expression patterns in cancer cells and normal cells. The normal cells used here as a reference were fibroblasts $(\mathrm{Fb})$ and mesenchymal stem cells (MSCs), cultured under both acidic and neutral environments. The information gathered in this comparative study should provide the basis for the development of novel and selective anticancer therapeutics.

The present study shows that RAB39A (RAB39A, Member of the RAS oncogene family) is a novel therapeutic target and that RXRB (Retinoid X Receptor Beta) is one of its major effectors. RAB39A is associated with the acidification of phagosomes during the maturation phase into lysosomes [8,9]. RXRB is a member of the retinoid $\mathrm{X}$ receptor ( $\mathrm{RXR}$ ) families mediating the effects of retinoic acid [10], and the mutual heterodimers with vitamin D receptor (VDR) are involved in cancer developments [11]. Even though RAB39A-RXRB axis has never been described as a therapeutic option for cancers, here, it is proved that targeting RAB39A-RXRB axis significantly impairs cancer stem cell (CSC) growth and survival. Thus, targeting RAB39A-RXRB axis is a promising therapeutic approach to specifically affect the $\mathrm{CSC}$ fraction of the total cancer cell population that is also 
the tumor cell fraction associated with chemoresistance, recurrence, and metastasis.

\section{RESULTS}

\section{RAB39A is a novel target for molecular anticancer therapeutic strategies}

As a first step, we compared global transcription differences of cancer cells and CSCs with normal cells cultured under acidic $\mathrm{pH}$ conditions versus neutral conditions. CSCs were enriched by sphere-forming culture, the most widely accepted method for isolating CSCs [12]. Under acidosis, we found that both cancer cells and CSCs showed up-regulation of pathways involved in DNA replication and cell proliferation (Supplementary Table 1). In contrast, $\mathrm{Fb}$ and MSCs that were maintained at low $\mathrm{pH}$ switched to inflammatory pathways (Supplementary Table 2). According to our previous data, this switch in $\mathrm{Fb}$ and MSCs may enhance invasiveness and metastatic potential of cancer cells, including CSCs $[7,13]$.

To identify novel molecular targets for the development of anticancer therapies, we performed a principal component analysis (PCA) on the global transcriptome data. Cancer cells, including CSCs differed from normal cells in the component 1 axis of PCA (Figure 1A). Among the top 100 gene elements on this axis (Supplementary Table 3), we selected 10 candidates, including RAB39A, CPVL, NUP210 and $L H X 2$, which were robustly expressed in cancer cells and CSCs but not in normal MSCs or Fb in both acidic and neutral environments (Figure 1B).

ShRNA-based stable knockdown of RAB39A, CPVL, $N U P 210$ and $L H X 2$ significantly impaired cancer cell growth under neutral and acidic conditions in HOS human osteosarcoma cells (Figure 1C and 1D), but had no effect on the growth of normal cells (Supplementary Figure 1A). As a result of this experiment, we considered these 4 candidate genes as promising therapeutic targets for cancer. We also identified four other genes from the component 1 axis as second-choice targets (Supplementary Figure 1B), namely, KCNG3, SLITRK5, FXYD6 and PRAME. Silencing of these latter genes inhibited cell growth in neutral conditions but not in acidic conditions (Supplementary Figure 1C). Similar effect was confirmed in HeLa human endocervical carcinoma cells (data not shown).

The stable knockdown of RAB39A in 143B human osteosarcoma cells, which originated from the same host of HOS cells and which are well-known to form xenotransplanted tumors in immunodeficient mice, resulted in a significantly lower rate of tumorigenicity following xenotransplantation into a mouse model compared to shControl-143B and the parental cells. Silencing of CPVL couldn't significantly affect in vivo tumor growth (Figure $1 \mathrm{E})$. The differences in rates of tumor development might result from the transplantability of each type of knockdown cell, and correspond to the variable survival rate of each type of knockdown cell at the initial stages of xenotransplantation, i.e., the poor tumorigenicity of $R A B 39 A$-knockdown cell was possibly related to the reduced cancer stemness in the cell. Indeed, cancer stemness is a phenotype that is associated with the ability to reproduce a similar tumor to the original one in immunodeficient mouse models, even after several passages in the cell culture $[12,14]$.

\section{Targeting RAB39A inhibits cancer stemness and tumorigenesis}

According to our previous results, sarcoma CSCs show a higher level of lysosomal acidity [15]. RAB39A is associated with the acidification of phagosomes during the maturation phase into lysosomes [8,9], and we thus speculated that CSCs are a good target for anti-RAB39A strategies. Here, we sought to confirm the effectiveness of RAB39A targeting for the CSC fraction of a tumor cell population, by knocking-down or over-expressing $R A B 39 A$ in parental 143B and HeLa cells via lentiviral transduction with specific vectors. We evaluated the proportion of the side population (SP) within the total tumor cell population. In 143B human osteosarcoma cells, the overexpression of $R A B 39 A$ increased the SP fraction whereas the knockdown of $R A B 39 A$ significantly decreased the SP fraction (Figure $2 \mathrm{~A}$ and $2 \mathrm{~B}$ ). Induced overexpression or knockdown of $R A B 39 A$ was confirmed by quantitative reverse transcription polymerase chain reaction (qRT-PCR) analysis (Figure 2C). RAB39A knockdown in 143B tumor cell population also impaired the expression of the stem cell marker CD44 compared to control (shCont) cells (Figure 2D and 2E). The results obtained with osteosarcoma cells were confirmed for HeLa cells in which we found a higher expression of the CXCR4 stem cell marker, a higher SP fraction in cells overexpressing RAB39A, and a reduced CXCR4 expression and SP fraction in cells with knockdown of $R A B 39 A$ (Supplementary Figure 2A to $2 \mathrm{~F}$ ). As an index of stemness, we also evaluated sphere-forming ability. This assay is the most widely accepted method for isolating CSCs [12] and is based on their capacity to grow as floating spheres in the absence of fetal serum. Sphere formation was significantly reduced after treatment with 2 types of $R A B 39 A$ knockdown, and silencing with either shRAB (4) or (5) (Figure 2F, Supplementary Figure $2 \mathrm{G})$ significantly affected the number and the size of the obtained spheres (Figure 2G, Supplementary Figure 2H).

In order to evaluate the impact of RAB39A on tumorigenesis, RAB39A-knockdown (shRAB) cells and control 143B (shCont) cells were injected subcutaneously at serially different cell dilutions into the left and right sides, respectively, of the backs of mice. After xenotransplantation, tumor volumes and tumorigenic rates were measured at 3 and 5 weeks. We observed a significantly lower rate of tumorigenicity in the left sides of mice with transplantation of $R A B 39 A$-knockdown 


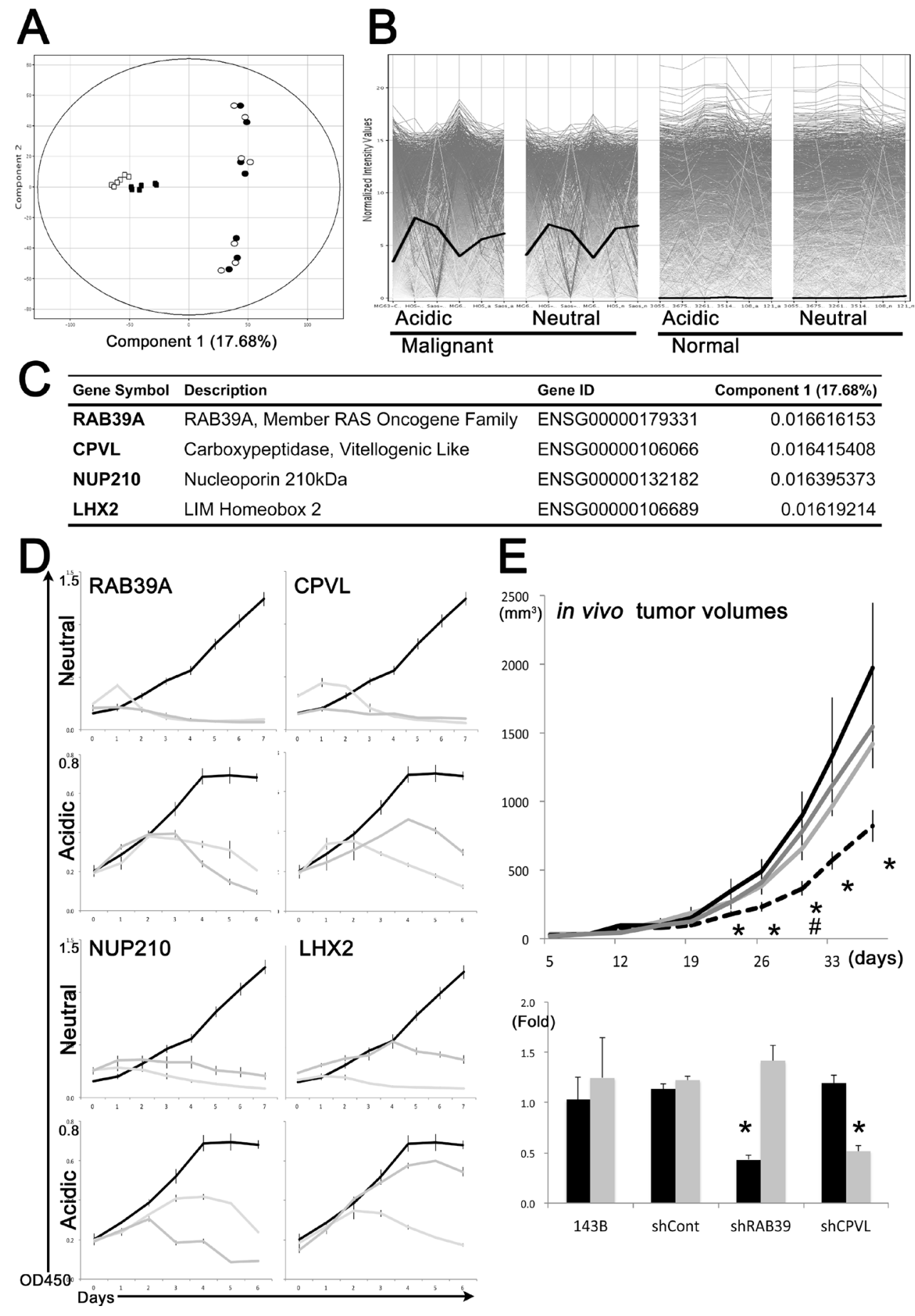

Figure 1: Transcriptional comparison, mathematical ranking and shRNA-based approaches for selection of candidate genes with the best ranking for cancer targeting. (A) Sarcoma cells were distinguished from normal cells by component 1 axis of a principal component analysis, followed by global transcriptome comparison. White and black indicate transcriptional status under neutral $(\mathrm{pH} 7.4)$ and acidic $(\mathrm{pH} 6.5)$ conditions, respectively. Round and square symbols indicate sarcoma and normal cells, respectively. (B) RAB39A (bold black line) shows higher expression values in malignant cells. Each line indicates the expression value of a gene. Genes expressed at low levels in normal cells but abundantly expressed in malignant cells were identified as targeting candidates, and used for shRNA-based screening. (C) RAB39A, CPVL, NUP210 and LHX2 are primary candidates for targeting cancer cells and CSCs. (D) Cell growth inhibition in neutral ( $\mathrm{pH}$ 7.4) and acidic ( $\mathrm{pH}$ 6.8) conditions in cells transfected with shRNAs against the selected genes. Black and 2 gray lines indicate growth of shControl and 2 kinds of gene-specific shRNA-treated HOS human osteosarcoma cells, respectively. (E) Upper graph, reduced tumor volumes in mice subcutaneously injected with RAB39A-knockdown 143B human osteosarcoma cells (black dotted line). Black, dark gray and light gray lines correspond to shControl, shCPVL and parental 143B cells, respectively. \#: ANOVA on Day 30; F $(3,20)=4.054, p=0.021{ }^{*} p<0.05$, by Fisher's PLSD, compared to shControl cells. Lower graph, silencing of $R A B 39 A$ and $C P V L$ expression (black and gray bars, respectively) in 143B xenotransplanted tumors with different cell lines was confirmed by qRT-PCR. 

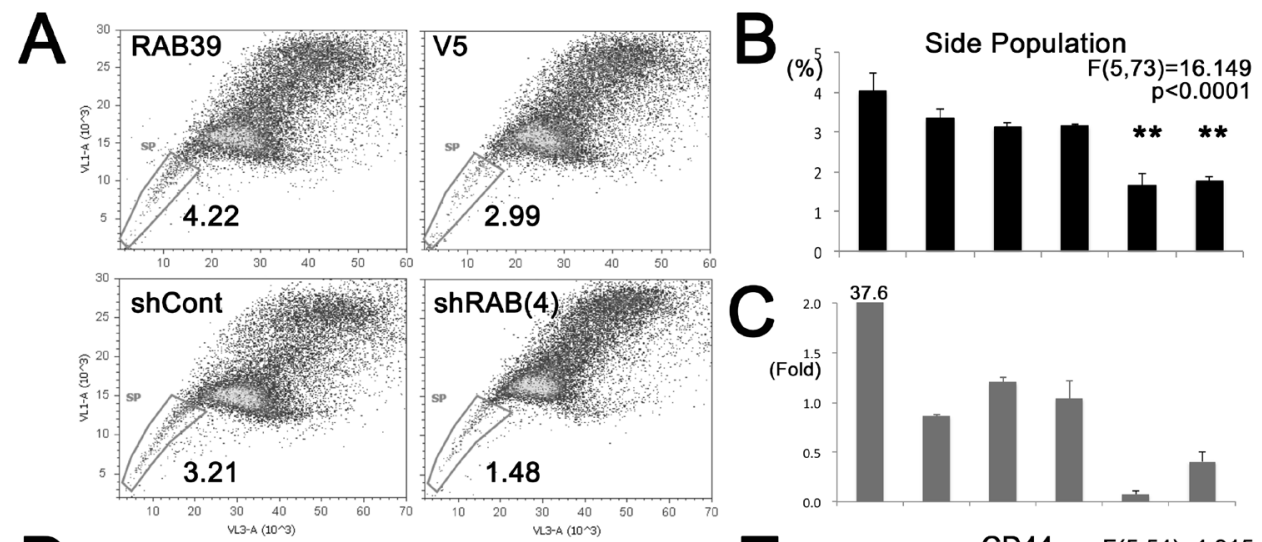

D


$\mathbf{G}^{\mathrm{m}}$

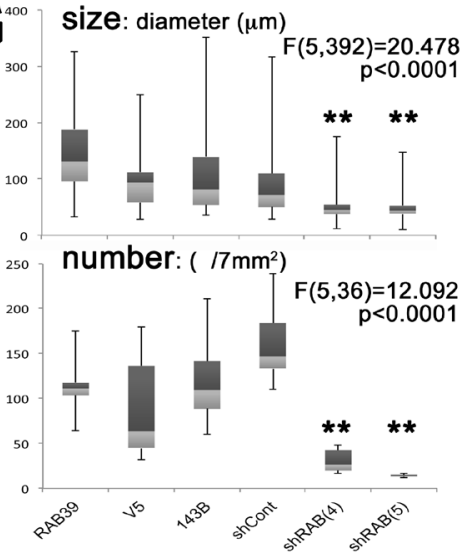

$\mathrm{H}$

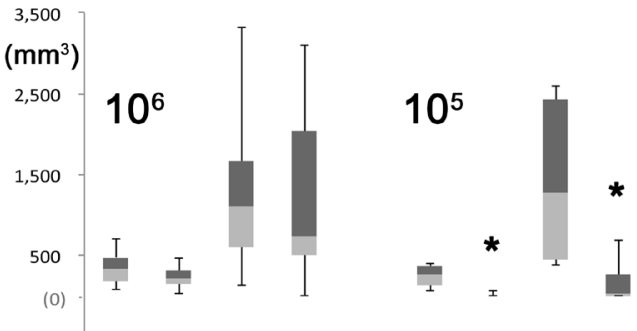

in vivo

$10^{4}$

tumor volumes

(\%) $100100100100 \quad 10016.7100 \quad 50 \quad 00016.7 \quad 0$ tumorigenic rates

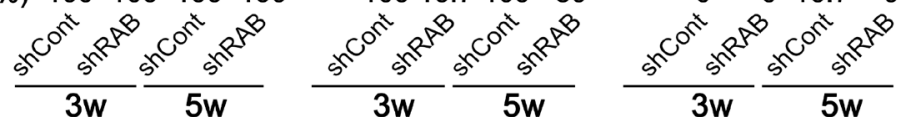

Figure 2: Knockdown of RAB39A reduces stemness and tumorigenicity. All experiments were performed using 143B cells. (A) Flow cytometry of SP fraction of cells transfected with different vectors: RAB39, cells transfected with RAB39A; control cells (V5), cells transfected with $R A B 39 A$ RNAi (shRAB(4)) or with control RNAi (shCont). (B) Graphic representation of data shown in panel A. In $R A B 39 A$ silenced cells, SP fractions were significantly reduced. (C) $R A B 39 A$ expression was confirmed by qRT-PCR. RAB39A knockdown used either shRAB (4) or shRAB (5). (D) Flow cytometry of CD44 expression. Left panel, RAB39 (black line) and V5 (gray line); right panel, shRAB (4) (black line) and shCont (gray line). (E) Graphic representation of data shown in panel D. Knockdown of $R A B 39 A$ significantly inhibited CD44 v9 expression. (F) Reduced rate of sphere formation after knockdown of RAB39A. Scale bar, $75 \mu \mathrm{m}$. (G) After knockdown of $R A B 39 A$, sphere size (diameter) and number were significantly reduced. ${ }^{* *} p<0.05$, by Fisher's PLSD, vs. shCont and parental 143B cells. (H) Six mice were xenotransplanted by subcutaneous injection with serial dilutions $\left(10^{6}-10^{4}\right)$ of tumor cells transfected with different vectors. With $10^{5}$-dilution, tumor volumes were significantly smaller than $R A B 39 A$ knockdown tumors (shRAB) at $3(p=$ $0.0048)$ and 5 weeks ( $p=0.0156$, Mann-Whitney $U$-test vs. shCont). Rates (\%) of tumorigenesis with respect to control tumors (shCont) are shown. shRAB and shCont correspond to shRAB (4) and shCont in the in vitro experiments. 
cells at a $10^{5}$ cell dilution at both time points (Figure $2 \mathrm{H}$, Supplementary Figure 3A).

\section{RXRB is the downstream effector for RAB39A- mediated induction of cancer stemness}

In order to identify the downstream pathways of RAB39A, which ultimately affect cancer stemness, we used RNA-seq to screen the RNA profile of spheres formed by $143 \mathrm{~B}$ and HeLa cells with knockdown of $R A B 39 A$. We compared transcription patterns in spheres obtained by silencing RAB39A (shRAB (4) and (5)) with spheres from parental cells, spheres from $R A B 39 A$ overexpressing cells (RAB39), and with control cells (shCont and V5, which are shRABs and RAB39 controls, respectively). We used stringent criteria to select candidate genes that showed at least 2-fold greater expression and were statistically replicated in spheres of $R A B 39 A$ knockdown cells; the fold differences and statistical significance were confirmed in both $143 \mathrm{~B}$ and HeLa cells (Table 1). The identified genes were processed using the "Pathway Analysis" software package (Strand NGS software version 2.0), and we focused on downregulated and up-regulated pathways (Table 2). "Notch Signaling", "Transcriptional activity of SMAD2-3-4 heterotrimer" and "Aryl Hydrocarbon Receptor" were identified as down-regulated pathways that are involved in NCOR2 inhibition. "Vitamin D Metabolism", "Nuclear Receptors", "Signaling by Retinoic Acid" and "Vitamin A and Carotenoid Metabolism" were identified as downregulated pathways that are involved in RXRB (Retinoid X Receptor Beta) inhibition. UGT2B15 and RIIAD1 were involved in the most important up-regulated pathways.

$R X R B$ inhibition resulting from $R A B 39 A$ silencing was also confirmed by qRT-PCR analysis in spheres obtained from both 143B and HeLa cells (Figure 3A and $3 \mathrm{~B})$, and in some cases was associated with the inhibition of NCOR2. UGT2B15 and RIIAD1 were increased, although not in all the $R A B 39 A$ silenced spheres (Figure $3 \mathrm{~A}$ and $3 \mathrm{~B}$ ). The stemness-related genes KLF4, SOX2, $N A N O G$ and POU5F1/OCT3 were analyzed and only $K L F 4$ was significantly reduced in $R A B 39 A$ silenced spheres from both $143 \mathrm{~B}$ and HeLa cells; this was also confirmed by qRT-PCR analysis (Figure $3 \mathrm{~A}$ and $3 \mathrm{~B}$ ). Sphere-forming ability was affected by the silencing of $R X R B$ in both $143 \mathrm{~B}$ and HeLa cells that were treated with 2 different knockdowns, shRXRB (7) and (8), and similarly, by the silencing of $R A B 39 A$ in cells treated with either shRAB (4) or shRAB (5) (Figure 3C and 3D).

To confirm that RXRB is a downstream effector of RAB39A that fosters cancer stemness, we induced overexpression of $R X R B$ in $R A B 39 A$-knockdown 143B cells and evaluated their sphere-formation ability and tumorigenesis in vivo. Overexpression of $R X R B$ in $R A B 39 A$-deficient cells completely restored the sphereforming ability (Figure $4 \mathrm{~A}-\mathrm{B}$ ). $R X R B$ overexpression in the analyzed models was confirmed both by qRT-
PCR (Figure 4C) and western blot analysis (Figure 4D). Additionally, overexpression of $R X R B$ restored the tumorigenicity of $R A B 39 A$-knockdown cells in xenografted mice (Figure 4E, Supplementary Figure $3 \mathrm{~B}$ ). In the V5 controls from 143B cells, $R A B 39 A$-knockdown (V5_shRAB) caused significant reduction in tumor volume and rates of tumorigenesis compared to control cells (V5_shCont). $R X R B$ overexpression in the RXRB shRAB cells restored tumor growth potential to the similar or more level as the RXRB shCont cells. Our data clearly demonstrated that RAB39A and its downstream molecular effector RXRB fostered cancer stemness and tumorigenesis, and that RAB39A-RXRB axis is a potential target for cancer therapies.

\section{RAB39A expression is crucial for the pathogenesis of different malignancies}

Hypoxia triggers cancer glycolysis and lysosomal acidification and is often associated with enhanced cancer stemness as it is a determinant of CSC evolution in vivo and in CSC niches [16]. As RAB39A is involved in lysosome maturation $[8,9]$ and, according to our presented data, also in cancer stemness, we investigated whether hypoxia might modulate the expressions of $R A B 39 A$ and $R X R B$, and mediate CSC survival under hypoxic conditions. We found that under hypoxia, $R A B 39 A$ expression significantly increased in various cancer cell types, including sarcoma cells. $R X R B$ was also induced by hypoxia in 5 out of 6 cancer cells, especially in HeLa and $143 \mathrm{~B}$ cells, even though it was reduced in MSC (Figure $5 \mathrm{~A})$. Furthermore, the silencing of $R A B 39 A$ significantly altered the viability of CSCs that were cultured under low oxygen tension conditions (Figure $5 \mathrm{~B}$ ), indicating that therapeutic targeting of $R A B 39 A$ might selectively impair CSCs in hypoxic areas of tumors.

To further validate RAB39A and RXRB as potential targets for cancer therapy, we analyzed their expression levels in various malignancies from clinical samples. To date, a high level of cytoplasmic expression of RXRB has been demonstrated in thyroid carcinoma [17]; however, the expression of $R A B 39 A$ has not been explored. Here, we found that $R A B 39 A$ was expressed in malignancies originating from adrenal, lymphoid, pancreas and testicular tissues, with a higher level of expression (often 100-fold higher) in clinical sarcoma samples than other types of cancers. $R X R B$ was expressed in different cancers, irrespective of the tumor histotype (Figure 5C). Our data conformed to The Cancer Genome Atlas (TCGA) database, indicating that $R A B 39 A$ was highly expressed in testicular germ cell tumor, glioblastoma, glioma, pheochromocytoma, lymphoma, leukemia, invasive breast cancers and sarcomas, etc; and that $R X R B$ was expressed more abundantly in all cancer histotypes (http://www.cbioportal.org/cross_cancer.do?session $\mathrm{id}=59 \mathrm{~d} 5 \mathrm{a} 712498 \mathrm{e} 5 \mathrm{df} 2 \mathrm{e} 296350 \mathrm{a}$; Supplementary Figure $4 \mathrm{~A}$ and $4 \mathrm{~B})$. Interestingly, $R X R B$ expression levels were 

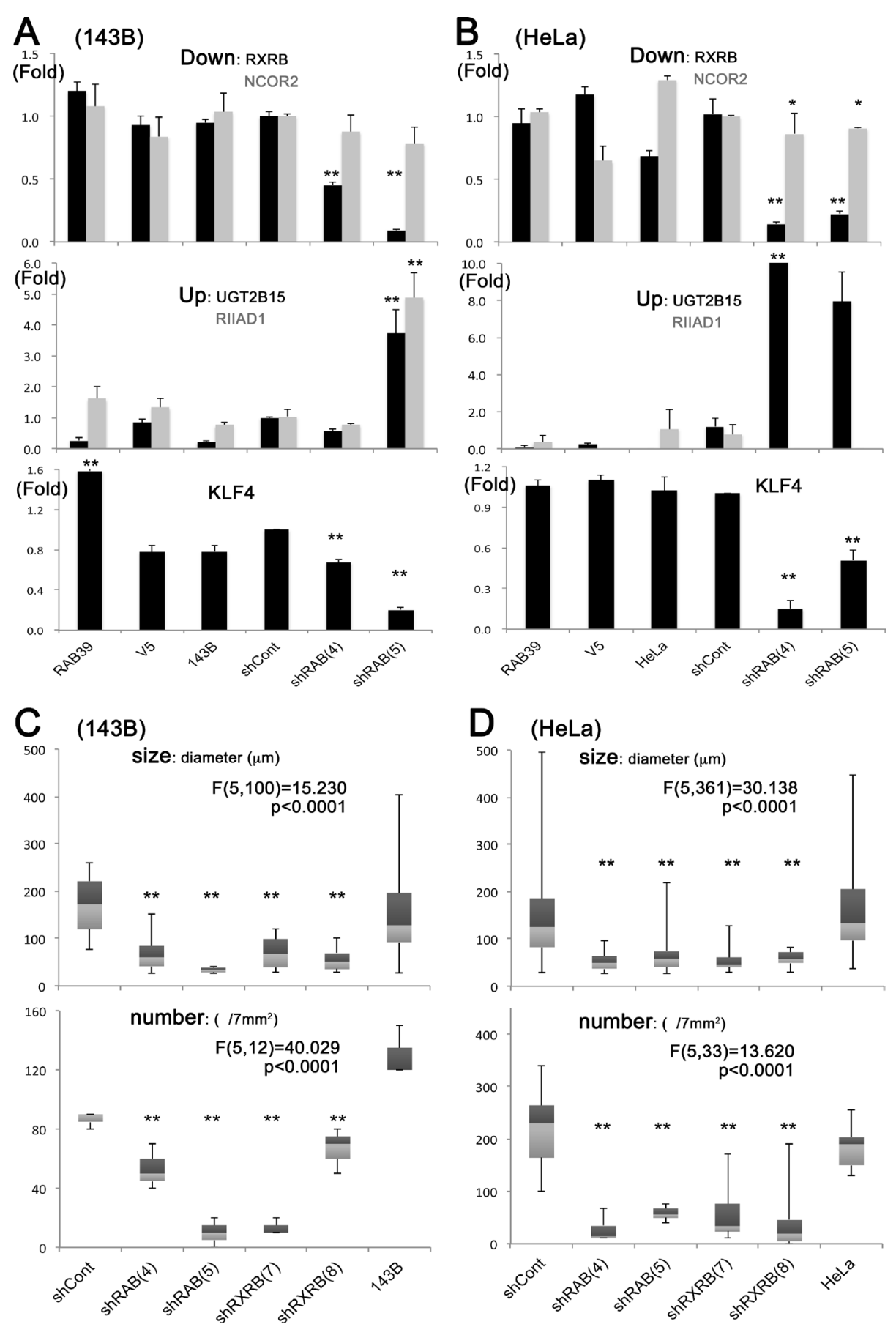

Figure 3: RXRB expression is strongly inhibited in RAB39A-silenced and slowly growing spheres, and its knockdown further impairs sphere formation. (A) Slowly growing spheres that were formed by $143 \mathrm{~B}$ cells silenced for $R A B 39 A$ expression with shRAB (4) and (5) (verified by qR-PCR). The upper panel shows $R X R B$ and NCOR2 inhibition of expression (black and gray bars respectively). ANOVA: $\mathrm{F}(5,15)=113.722, p<0.0001$ for $R X R B ; \mathrm{F}(5,18)=0.761, p=0.5893$ for $N C O R 2$. The middle panel shows $U G T 2 B 15$ and RIIAD1 induction of expression (black and gray bars, respectively). ANOVA: $\mathrm{F}(5,18)=16.529, p<0.0001$ for $U G T 2 B 15$; $\mathrm{F}(5,12)=16.074, p<0.0001$ for RIIAD1. On the lower panel, KLF4 is enhanced in RAB39A-induced cells and inhibited in the silenced cells. ANOVA: $\mathrm{F}(5,13)=188.165, p<0.0001$ for KLF4. (B) qRT-PCR validation in HeLa cells was performed similarly to A. ANOVA: F $(5,16)=36.718, p<0.0001$ for $R X R B ; \mathrm{F}(5,18)=6.449, p<0.0001$ for $N C O R 2 ; \mathrm{F}(5,18)=10.707, p<0.0001$ for $U G T 2 B 15 ; \mathrm{F}(5,12)$

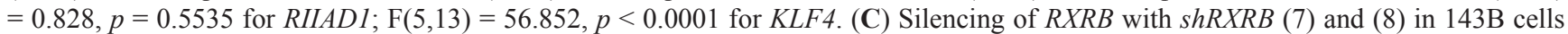
reduces sphere size (diameter) and number to a similar extent as that obtained by RAB39A silencing with shRAB (4) and (5). ANOVA: $\mathrm{F}(5,100)=15.230, p<0.0001$ for size; $\mathrm{F}(5,12)=40.029, p<0.0001$ for number. (D) Sphere-forming assay in HeLa cells, performed similarly to C. ANOVA: $\mathrm{F}(5,361)=30.138, p<0.0001$ for size; $\mathrm{F}(5,33)=13.620, p<0.0001$ for number. Statistical evaluations in A-D were performed with one-way factorial ANOVA accompanied by Fisher's PLSD test. In Fisher's PLSD, ${ }^{* *} p<0.05$ vs. parental and controls (V5 or shCont), ${ }^{*} p<0.05$ vs. parental cells. 



\section{RXRB}

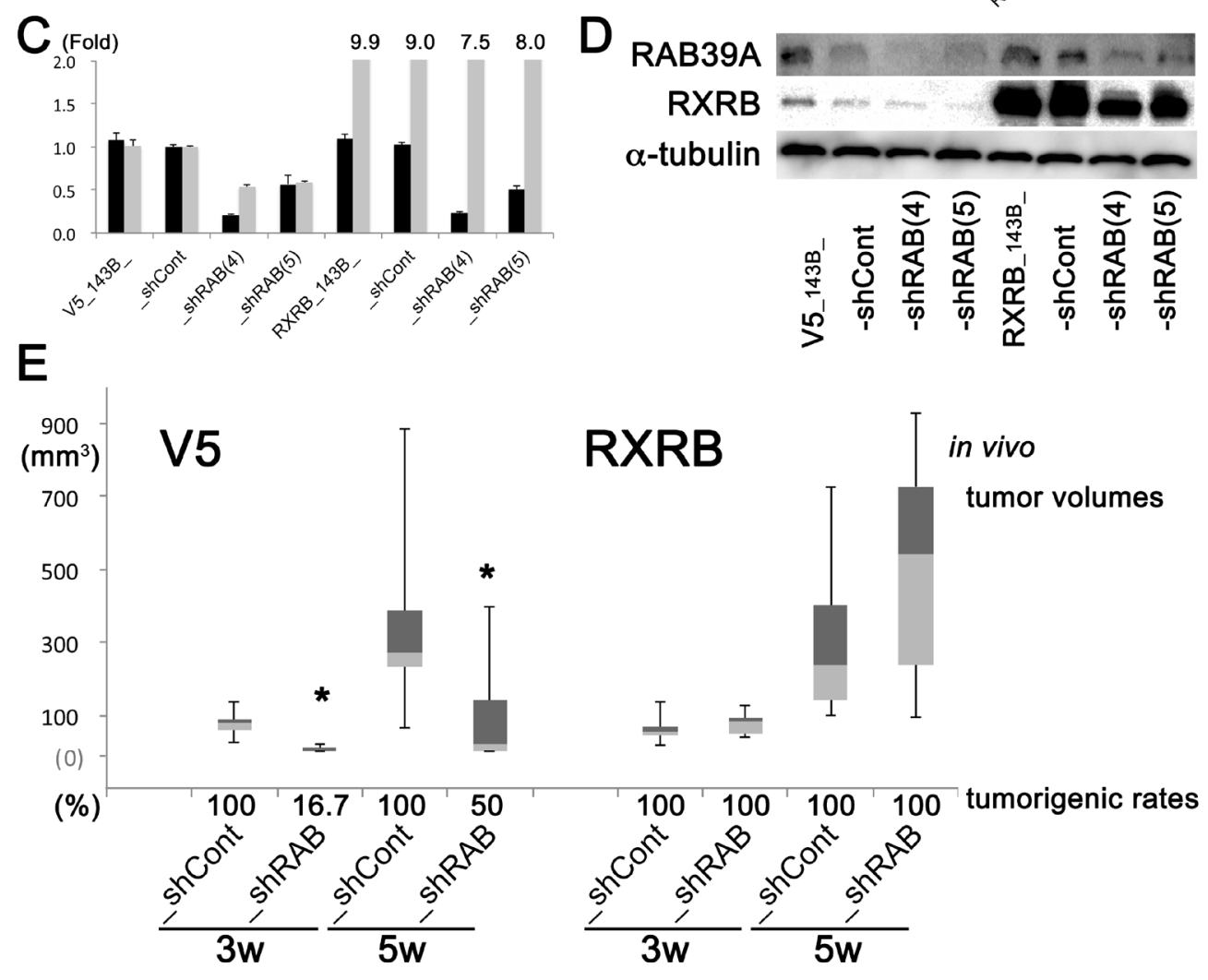

Figure 4: Viral transduction of RAB39A-silenced cells with RXRB restores spherogenicity in vitro, and tumorigenicity in vivo. (A) Silencing of RAB39A expression using a V5 sequence-containing vector strongly affected sphere formation (shRAB (4) and (5) silenced variants vs. shCont) of 143B cells. This effect was lost when cells were transduced with an $R X R B$ containing viral vector. Scale bar, $75 \mu \mathrm{m}$. (B) Sphere size (diameter) and number of spheres are shown in the panel A. ANOVA: In V5 group, F $(2,120)=7.347, p$ $=0.0010$ for size; $\mathrm{F}(2,30)=3.399, p=0.0467$ for number; ${ }^{*} p<0.05$, Fisher's PLSD vs. shCont. In RXRB group, sphere-forming ability was completely restored with $R A B 39 A$-deficient cells. $\mathrm{F}(2,165)=0.214, p=0.8077$ for size; $\mathrm{F}(2,30)=1.070, p=0.3557$ for number. $(\mathbf{C})$ qRT-PCR analysis of RAB39A and $R X R B$ (black and gray bars, respectively) in 143B transduced cells for $R A B 39 A$ inhibition and $R X R B$ induction. (D) Data shown in panel C for $R A B 39 A$ and $R X R B$ were confirmed by Western blot analysis. $R X R B$ transduced variants have a higher level of the RXRB protein. (E) After subcutaneous injection of mice with $10^{5}$ tumor cells that were previously transduced with V5or $R X R B$-carrying vectors, tumor volumes and tumorigenic rates were measured. In the V5-control group, tumor volumes were significantly smaller in $R A B 39 A$-silenced tumors (shRAB) (at 3 weeks, $p=0.0033$; at 5 weeks, $p=0.0360$, Mann-Whitney $U$-test vs. shCont). The induced expression of $R X R B$ restored the tumorigenicity of $R A B 39 A$-silenced $143 \mathrm{~B}$, as shCont and shRAB showed similar tumor volumes and tumorigenic rates. shRAB and shCont correspond to shRAB (4) and shCont in the in vitro experiments. 

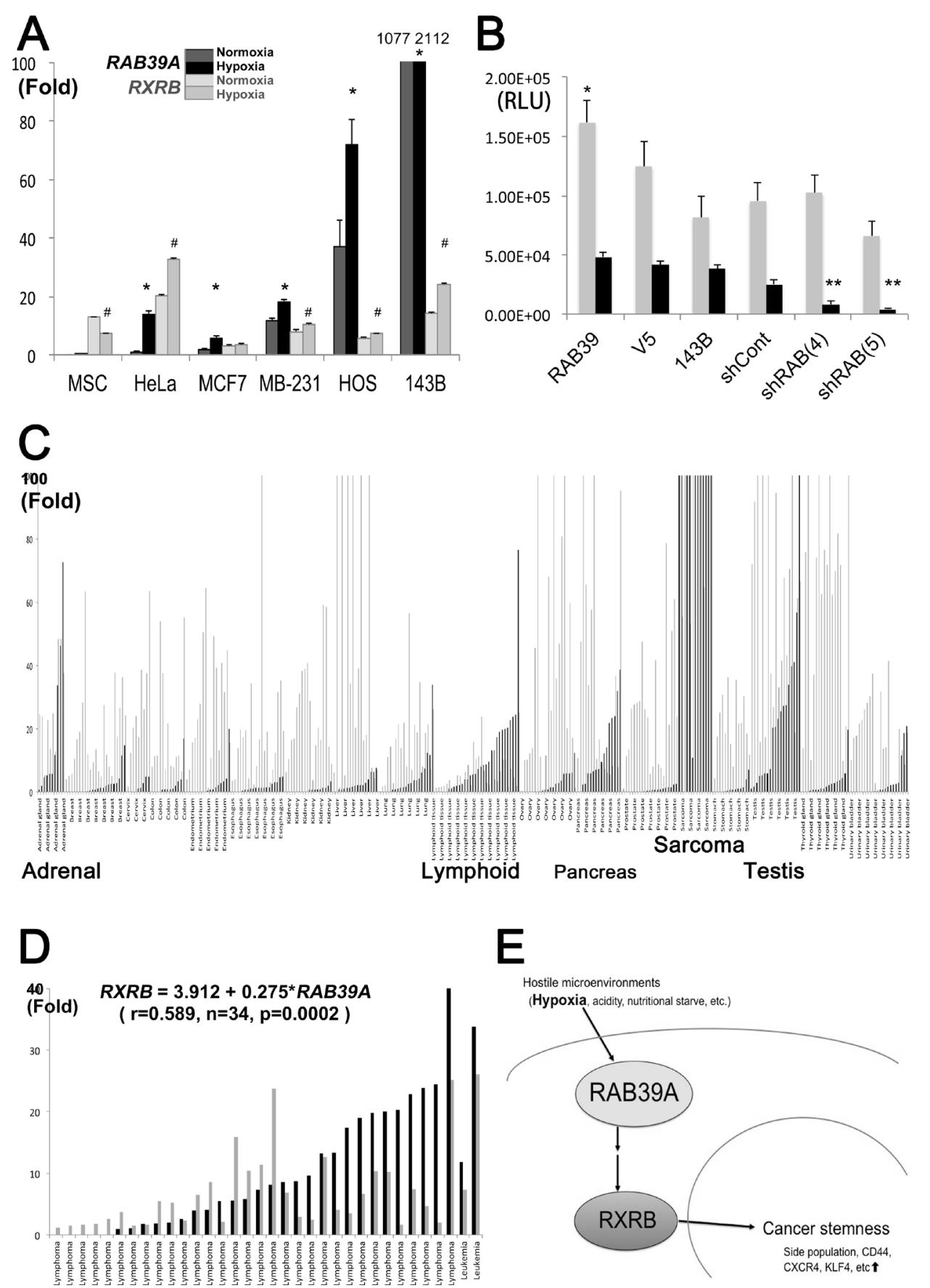

Figure 5: RAB39A function and expression in cancer. (A) Fold changes in expression of $R A B 39 A$ (2 kinds of black bars) and $R X R B$ ( 2 kinds of gray bars) under normoxia (lighter blacks or grays), and under $1 \% \mathrm{O}$, hypoxia (darker blacks or grays), in various types of cancer cell. Hypoxia induces $R A B 39 A$ and $R X R B$, which were confirmed by qRT-PCR; $\triangle \mathrm{Ct}$ value of HeLa cells under normoxia is shown as 1 or 20 , respectively corresponding to $R A B 39 A$ or $R X R B .{ }^{*}(R A B 39 A)$ or \# (RXRB), $p<0.05$, Mann-Whitney $U$-test vs. each normoxic culture. (B) Viability under normoxia and hypoxia (gray and black bars, respectively) of $R A B 39 A$-silenced spheres obtained from different $R A B 39 A$ variants was measured as luminescence values in 143B cells. The data were analyzed using one-way factorial ANOVA coupled to Fisher's PLSD test. For normoxia (gray bars), ANOVA: F $(5,30)=4.050, p=0.0063,{ }^{*} p<0.05$, significant by Fisher's PLSD vs. $143 \mathrm{~B}$ cells. For hypoxia (black bars), ANOVA: F $(5,24)=28.864, p<0.0001,{ }^{* *} p<0.05$, vs. shCont and parental 143B cells. (C) qRT-PCR analysis of $R A B 39 A$ and $R X R B$ expression in various human malignancies. $R A B 39 A$ (black bars) was mainly expressed in sarcomas and malignancies originating from adrenal, lymphoid, pancreas and testicular tissues, whereas $R X R B$ (gray bars) was more widely expressed, irrespective of tumor histotypes. Each $R A B 39 A$ or $R X R B$ value in the control normal sample was indicated as 1 or 20 , respectively, for the representation. Generally, $\triangle \mathrm{Ct}$ values to ACTB were 5-8 fold higher in $R X R B$ than that of $R A B 39 A$ in TaqMan ${ }^{\circledR}$ qRT-PCR. (D) $R A B 39 A$ and $R X R B$ expressions in lymphoid malignancies. The fold increases of $R A B 39 A$ (black bars) and $R X R B$ (gray bars) are shown, and the positive correlation is significantly indicated $\left(R X R B=3.912+0.275^{*} R A B 39 A, \mathrm{r}=0.589, n=34, p=0.0002\right.$; Pearson's correlation coefficient). (E) Hostile microenvironments like hypoxia induce RAB39A and its downstream effector RXRB, fostering cancer stemness and tumorigenesis. 
significantly correlated with $R A B 39 A$ expression levels only in tumor tissues ( $\mathrm{r}=0.205, n=325, p=0.0002)$ and not in normal tissues $(\mathrm{r}=0.202, n=69, p=0.0968)$. The highest level of correlation was found in lymphoid malignancies $\left(R X R B=3.912+0.275^{*} R A B 39 A, \mathrm{r}=0.589\right.$, $n=34, p=0.0002$; Figure 5D). Together, the clinical sample data strengthen our hypothesis that RXRB is a downstream effector of RAB39A, and that RAB39Atargeting treatments will selectively affect cancer cells and be unlikely to cause undue side effects in normal tissues.

\section{DISCUSSION}

In the present study, we used global transcriptomics, PCA and shRNA-based function screening to investigate the roles of RAB39A, CPVL, NUP210, LHX2, KCNG3, SLITRK5, FXYD6 and PRAME expression in cancer cells, including CSCs, under both acidic and neutral microenvironmental conditions. Our results indicate that these genes are selective therapeutic targets in cancer cells. Some of the candidate genes have previously been shown to be involved in cancer development [18-27], confirming the reliability of the procedure used here to detect cancer-specific targets. Among the candidate genes, $R A B 39 A$ appears to be very promising since its knockdown had a clear impact on tumorigenicity in vivo, especially during the early steps of tumor formation, when cancer stemness has a major role. Therefore, we suggest that RAB39A is involved in cancer stemness regulation.

Rab proteins are the largest family among the Raslike small GTPase superfamily, and control vesicular trafficking. Indeed, RAB39A function is associated with late endosomes and lysosomes, and regulates endocytosis and acidification of maturing phagosomes [8, 28]. RAB39A may thus be crucial for tumorigenesis since these processes are also linked to autophagy, which has an established role in cancer [29]. In autophagy, RAB39A negatively regulates LPS-induced autophagosome formation, and secretion of pro-inflammatory compounds, possibly through the involvement of the PI3K pathway [8, 9]. Our previous report showed a clear connection between lysosomal acidification and cancer stemness [15], and we thus speculated that CSCs are particularly good targets for anti-RAB39A therapeutic strategies. In agreement with our speculation, our data clearly demonstrated that targeting RAB39A inhibits cancer stemness and tumorigenesis. This is the first time that RAB39A has been studied in cancer biology, with the exception of a report on mouse Neuro2A cells and their involvement in neuronal differentiation, such as retinoic acid-induced neurite morphology [30].

In order to further explore the RAB39A downstream pathways that affect cancer stemness, we used RNA-seq to screen spheres produced by cells with a knockdown of $R A B 39 A$ expression. In combination with a cellular functional analysis following RAB39A knockdown and $\mathrm{RXRB}$ augmentation, this strategy enabled us to identify RXRB as a downstream effector of RAB39A that fosters cancer stemness. RXRB is a member of the RXR family of nuclear receptors that mediates the effects of retinoic acid, and it forms heterodimers with the retinoic acid receptor (RAR), thyroid hormone and VDR, increasing both DNA binding and transcriptional function on their respective response elements [10]. RXRB is widely expressed and plays a crucial role in spermatogenesis [31-33]. Furthermore, the mutual heterodimers between RXR and VDR are involved in cancer developments, and activated Ras-Raf-MAPK-ERK can engage in the classical VDR pathway to modulate variously gene expressions [11]. Ras-like small GTPase activity contained in RAB39A may contribute to cancer developments through RXR and VDR signaling. RXRB is also expressed in various malignancies $[17,34-38]$ and promotes cell survival/proliferation in triple-negative breast cancer [39], thus indirectly confirming a crucial role of the RAB39A-RXRB axis in modulating cancer stemness. In addition, TCGA database showed that genetic amplification of $R A B 39 A-R X R B$ was often seen in various types of malignancies especially like breast and neuroendocrine prostate cancers (Supplementary Figure 4C), suggesting that the RAB39A-RXRB axis plays a prominent role for development of various malignancies.

Intratumoral hypoxia is a widely accepted characteristic of CSC evolution in vivo and in CSC niches [16]. We focused on evaluating the expression of $R A B 39 A$ under hypoxic conditions and the effects of its inhibition. Our data showed that $R A B 39 A$ expression increased in hypoxic cancer cells and that its inhibition significantly reduced the viability of hypoxic CSCs. Hypoxia is a trigger of cancer glycolysis; lysosomal compartmentalization is the most effective detoxification mechanism for high proton intracellular contents associated with glycolysis, and RAB39A activity might therefore be required for lysosomal acidification $[8,9,28]$. Taken together, our data from the preclinical model strongly suggested that targeting the RAB39A-RXRB axis might result in selective impacts on CSCs in hypoxic areas of tumors.

Through analyses of both clinical samples and TCGA database, we confirmed that $R A B 39 A$ was expressed in sarcomas and malignancies of lymphoid, adrenal and testicular tissues; and $R X R B$ abundance was constantly widespread in various cancers, suggesting that RXRB functions with the saturated level in cancers. Induced $R X R B$ showed the restoration of both spherogenesis and tumorigenesis, but further increase of its expression couldn't significantly enhance these abilities. On the contrary, silencing of $R X R B$ or $R A B 39 A$ inhibited the spherogenicity with a major and significant effect, possibly through impairment of the stemness. These data suggest that $\mathrm{RXRB}$ functioning protein is at almost saturated activity and that RXRB-mediated cancer stemness has been already maximized in various cancers. It is why inhibiting RAB39A or RXRB can critically affect cancer stemness. In the clinical sample analysis, $R X R B$ levels were not correlated with $R A B 39 A$ expression levels in normal tissues, but a significant correlation was present in tumor tissues. These 
Table 1: Genes that were significantly changed in RAB39A-silenced and slowly growing spheres

\begin{tabular}{|c|c|c|c|}
\hline Down_Gene Symbol & Gene ID & Fold Change* & $p$-values (Corr) ${ }^{* *}$ \\
\hline MIR3916 & 100500849 & -4.2365184 & 0 \\
\hline JMY & 133746 & -2.0020356 & 0 \\
\hline $\mathrm{AMH}$ & 268 & -5.758692 & 0 \\
\hline SNORD35B & 84546 & -2.877896 & 0 \\
\hline TSEN54 & 283989 & -2.6107361 & 0 \\
\hline SNORD117 & 692233 & -2.8293664 & 0 \\
\hline FBRSL1 & 57666 & -2.243737 & 0 \\
\hline MIR23A & 407010 & -2.193306 & 0 \\
\hline SNORA23 & 677808 & -3.2678993 & 0 \\
\hline PIGW & 284098 & -2.149463 & 0 \\
\hline SNORA8 & 654320 & -4.5891285 & 0.02020202 \\
\hline LOC100288162 & 100288162 & -2.2554677 & 0.02020202 \\
\hline RFNG & 5986 & -2.2187188 & 0.02020202 \\
\hline SNORA9 & 677798 & -2.9003572 & 0.02020202 \\
\hline RXRB & 6257 & -2.4855814 & 0.02020202 \\
\hline CHSY1 & 22856 & -2.0405383 & 0.030303031 \\
\hline NCOR2 & 9612 & -2.1620538 & 0.030303031 \\
\hline STX16 & 8675 & -2.0439882 & 0.030303031 \\
\hline SNX25 & 83891 & -2.3050969 & 0.030303031 \\
\hline ZNF524 & 147807 & -3.4322982 & 0.030303031 \\
\hline SNORA55 & 677834 & -2.3716238 & 0.04040404 \\
\hline SSH1 & 54434 & -2.002753 & 0.04040404 \\
\hline \multicolumn{4}{|l|}{ Up_Gene Symbol } \\
\hline RIIAD1 & 284485 & 3.8731875 & 0 \\
\hline LOC101929741 & 101929741 & 7.2783465 & 0 \\
\hline LINC00240 & 100133205 & 3.3969362 & 0 \\
\hline LINC00845 & 100507058 & 5.435211 & 0 \\
\hline TRIM64B & 642446 & 6.6734176 & 0 \\
\hline C17orf98 & 388381 & 5.1731205 & 0 \\
\hline PYY & 5697 & 4.068584 & 0 \\
\hline NAPSA & 9476 & 4.2063127 & 0 \\
\hline MAGEB10 & 139422 & 4.031648 & 0 \\
\hline ITIH6 & 347365 & 6.3592973 & 0 \\
\hline UGT2B15 & 7366 & 10.825695 & 0.02020202 \\
\hline LY6D & 8581 & 2.8018305 & 0.02020202 \\
\hline LOC100507377 & 100507377 & 3.4407458 & 0.02020202 \\
\hline LOC100506700 & 100506700 & 6.667328 & 0.030303031 \\
\hline
\end{tabular}

*These genes were statistically down- or up-regulated in RAB39A-silenced and slowly growing spheres.

${ }^{* *}$ Replicate analysis (Strand NGS); Moderate T test followed by Westfall Young correction was performed between RAB39A-knockdowns and the other spheres. Genes showing significant changes in expression in RAB39A-silenced and slowly growing spheres. RNA-seq analyses of 143B and HeLa cell spheres were used to obtain transcription profiles of slow growing cancer spheres in which expression of RAB39A had been silenced (shRAB(4) and (5)), for comparison to fast growing spheres, including parental cultures, RAB39A-overexpressing cells (RAB39), and transduced controls (V5 and shCont). Genes that were up-regulated or down-regulated $>2$-fold were selected as candidates; these were statistically confirmed in the analysis of both 143B and HeLa spheres. T-test followed by Westfall Young correction was performed using "Replicate analysis" (Strand NGS software version 2.0).

observations additionally support our hypothesis that RXRB is a downstream effector of RAB39A, and that targeting RAB39A will selectively affect cancer and CSCs and be unlikely to cause undue side effects in normal tissues.

In conclusion, this study has identified and validated
RAB39A as a promising therapeutic target in various human malignancies. We demonstrated that RAB39ARXRB axis plays a prominent role in cancer development and stemness, and that targeting RAB39A and inhibiting its downstream molecular effecter RXRB strongly 
Table 2: Pathways affected by RAB39A reduction in CSC spheres

\begin{tabular}{|c|c|c|c|}
\hline Down_Pathway & $\begin{array}{l}\text { Pathway } \\
\text { Entities }{ }^{\#}\end{array}$ & $\begin{array}{l}\text { Matched } \\
\text { Entities * }\end{array}$ & $p$-value ** \\
\hline Hs_Notch_Signaling_Pathway_WP268_70096 & 46 & 2 & $2.88 \mathrm{E}-04$ \\
\hline Hs_Vitamin_D_Metabolism_WP1531_82221 & 11 & 1 & 0.005967482 \\
\hline $\begin{array}{l}\text { Hs_Post-translational_modification-_synthesis_of_GPI- } \\
\text { anchored_proteins_WP1887_83233 }\end{array}$ & 26 & 1 & 0.013513307 \\
\hline Hs_Nuclear_Receptors_WP170_71083 & 38 & 1 & 0.020471161 \\
\hline Hs_Signaling_by_Retinoic_Acid_WP3323_83286 & 42 & 1 & 0.0226026 \\
\hline $\begin{array}{l}\text { Hs_Vitamin_A_and_Carotenoid_Metabolism_WP716_ } \\
83589\end{array}$ & 43 & 1 & 0.023134766 \\
\hline $\begin{array}{l}\text { Hs_miRNAs_involved_in_DNA_damage_response_ } \\
\text { WP1545_84697 }\end{array}$ & 69 & 1 & 0.024729608 \\
\hline $\begin{array}{l}\text { Hs_Transcriptional_activity_of_SMAD2-SMAD3-SMAD4_ } \\
\text { heterotrimer_WP2755_83472 }\end{array}$ & 48 & 1 & 0.024729608 \\
\hline Hs_Aryl_Hydrocarbon_Receptor_WP2586_85335 & 48 & 1 & 0.025260668 \\
\hline Hs_Pre-NOTCH_Expression_and_Processing_WP2786_83418 & 68 & 1 & 0.027382156 \\
\hline \multicolumn{4}{|l|}{ Up_Pathway } \\
\hline Hs_Tamoxifen_metabolism_WP691_85084 & 21 & 1 & 0.007245274 \\
\hline Hs_Glucuronidation_WP698_79224 & 26 & 1 & 0.00896314 \\
\hline Hs_Endothelin_Pathways_WP2197_74852 & 33 & 1 & 0.011020934 \\
\hline Hs_Surfactant_metabolism_WP3579_83469 & 36 & 1 & 0.011363514 \\
\hline Hs_Phase_II_conjugation_WP1880_83364 & 97 & 1 & 0.031381793 \\
\hline
\end{tabular}

"The gene number on the pathway, according to the database.

*The number of genes that were statistically down- or up-regulated in poorly grown cancer-spheres.

${ }^{* *}$ Pathway analysis (Strand NGS); Fisher exact test was performed between the Entity List of down-regulated genes and WikiPathway. Pathways affected by RAB39A reduction in CSC spheres. Using RNA-seq analysis of 143B and HeLa sphere cultures, we profiled transcription in RAB39A-knockdown spheres (shRAB (4) and (5)) in respect to untreated spheres, RAB39A-overexpressing spheres (RAB39), and controls (V5 for RAB39, and shCont for shRAB (4) and (5)). We selected genes with 2-fold higher or lower expression in RAB39A silenced spheres, and that were also confirmed to be statistically reproducible in a HeLa sphere model. Then, the pathways associated with the selected candidate genes were identified by using the "Pathway Analysis" software package (Strand NGS software version 2.0).

impairs tumorigenesis and cancer stemness (Figure 5E), with particular regard to musculoskeletal sarcomas and lymphoid malignancies. RAB39A and RXRB thus deserve further investigation that will allow the development of novel drugs for more effective and novel anti-cancer therapeutic strategies.

\section{MATERIALS AND METHODS}

\section{Cell lines}

Human osteosarcoma cells (MG-63, HOS) and normal fibroblasts (TIG-108, TIG-121) were obtained from the Japanese Collection of Research Bioresources (Osaka, Japan). Primary cultures of mesenchymal stromal cells (MSCs) (\#305526, \#351482, \#326162, \#367500) were acquired from Lonza (MD). Saos-2 human osteosarcoma cells were obtained from RIKEN BioResource Center (RIKEN BRC, Tsukuba, Japan).
HeLa human endocervical carcinoma and 143B human osteosarcoma cells were obtained from the American Type Culture Collection (ATCC, Manassas, VA). Cells were cultured in Dulbecco's modified Eagle's medium containing $10 \%$ fetal bovine serum, supplemented with penicillin (50 units $/ \mathrm{mL}$ ) and streptomycin $(50 \mathrm{mg} / \mathrm{mL})$ with $10 \mathrm{mM}$ 4-(2-hydroxyethyl)-1-piperazineethanesulfonic acid to achieve $\mathrm{pH} 7.4$, or with $10 \mathrm{mM}$ piperazine-1,4bis(2-ethanesulfonic acid) to achieve $\mathrm{pH}$ 6.5. Cells were incubated at $37^{\circ} \mathrm{C}$ in a humidified chamber supplemented with $5 \% \mathrm{CO}_{2}$.

\section{Sphere-forming culture}

Briefly, osteosarcoma cells with or without lentiviral transfection were cultured in 6-well plates $(30,000$ cells/well) coated with polyhema (Sigma-Aldrich) in anchorage-independent conditions. DMEM-F12 complete medium was used at either $\mathrm{pH} 6.5$ or 7.4. Progesterone 
(20 $\mathrm{nM})$, putrescine $(10 \mathrm{mg} / \mathrm{mL})$, sodium selenite $(30$ $\mathrm{nM})$, apo-transferrin $(100 \mathrm{mg} / \mathrm{mL})$, and insulin $(25 \mathrm{mg} /$ $\mathrm{mL}$ ) (Sigma-Aldrich) were added to the complete medium. Fresh human epidermal growth factor $(20 \mathrm{ng} / \mathrm{mL})$ and basic fibroblast growth factor $(10 \mathrm{ng} / \mathrm{mL})$ (GibcoLife Technologies) were added twice a week. After 10 days, bright field images were acquired using a Leica DMI4000B (Leica Microsystems). Only spheres with a diameter of more than $20 \mu \mathrm{m}$ were counted. Analysis of cell diameter was performed with Leica Application Suite Software (Leica Microsystems).

\section{RNA extraction and RNA-Seq analysis}

Total RNA from cell cultures or from spheres was extracted using guanidinium thiocyanate-phenol-chloroform. The total RNA was quantified with a Bioanalyzer (Agilent, Santa Clara, CA) following the manufacturer's instructions. A RIN (RNA Integrity Number) of 10 and an A260/A280 ratio over 1.8 were obtained for the total RNA.

Following the manufacturer's protocol, the library of template molecules for high throughput DNA sequencing was converted from the total RNA using TruSeq RNA Sample Prep Kit v2 (Illumina, San Diego, CA). For detecting RAB39A-cancer stemness pathways, the library was prepared from the total RNA isolated from spheres, using the Ribo-Zero rRNA Removal Kit (Illumina). The library was quantified with a Bioanalyzer (Agilent) following the manufacturer's instructions. The library (4 pM) was subjected to cluster amplification on a Single Read Flow Cell v4 with a cluster generation instrument (Illumina). Sequencing was performed on Genome Analyzer GAIIx for 76 cycles or HiSeq 2500 for 101 cycles using Cycle Sequencing v4 reagents (Illumina).

Image analysis and base calling were performed using Off-Line Basecaller Software 1.6 (Illumina). Human genome build 19 (hg19) was downloaded from the University of California, Santa Cruz genome browser (http://genome.ucsc.edu/) as the analytical reference. Reads were aligned using Strand NGS software (version 2.0, Strand Scientific Intelligence Inc., San Francisco, CA) with the sequence data sets. Transcript coverage for every gene locus was calculated from the total number of filter reads that mapped to exons. These analyses and filtering were performed using default parameters. All the advanced analyses for quantification with TMM normalization algorithm, expression analysis, pathway analysis with WikiPathway data, and principal component analysis were also performed using Strand NGS software. Genes with significantly different expressions were identified by the fold change method (fold change $>2$ ), statistically analyzed by Westfall-Young permutation procedure ( $p$ $<0.05$ ), and categorized into particular pathways using Pathway analysis $(p<0.05)$. All new data has been deposited in DDBJ/EMBL/GenBank under DRA004087, DRA004091 and DRA005595.

\section{Plasmid DNA and gene transfer}

Lentiviral shRNA vectors for $R A B 39 A(\operatorname{shRAB}(4)$ and (5)), RXRB ( $\operatorname{shRXRB}(7)$ and (8)), non-silencing control (shCont) and the other targets (CPVL, NUP210, LHX2s, KCNG3, SLITRK5, FXYD6 and PRAME) were purchased from Dharmacon (GE Healthcare, UK). Lentiviral cDNA vectors for RAB39A and RXRB were obtained from Dharmacon and OriGene (MD), respectively. V5 sequence-containing pLenti6 vector (Invitrogen, Thermo, MA) without any specific cDNA, was used as the overexpression control. Lentivirus transferring shRNA or cDNA were prepared with Lenti-X ${ }^{\mathrm{TM}}$ HTX packaging system (Clontech, Takara Bio, Shiga, Japan) according to the manufacturer's instructions. HOS, HeLa and 143B cells transferred by $>20$ MOI of each lentivirus were selected in the presence of $3 \mu \mathrm{g} / \mathrm{ml}$ puromycin or $10 \mu \mathrm{g} / \mathrm{ml}$ blasticidin, expanded and used in the experiments.

\section{WST-8 assay for cell viability}

HOS and HeLa cells were cultured in 96-well plates at a density of $1 \times 10^{3}$ per well, and cell viability assays were carried out by a Cell Counting Kit- 8 (Dojindo Molecular Technologies Inc, Kumamoto, Japan). WST8 reagent solution was added to each well, and the absorbance at $450 \mathrm{~nm}$ (OD450) was measured by a microplate reader after the microplate was incubated with the reagent for 2 hours at $37^{\circ} \mathrm{C}$, in accordance with the manufacturer's instructions.

\section{Mice and xenografting of human osteosarcoma cells}

Seven-week-old BALB/c nu/nu nude mice (CLEA Japan, Inc., Tokyo, Japan) transplanted with either 143B human osteosarcoma cells or genetically manipulated variants were used in the experiments. A minimum of 6 mice was xenotransplanted with $143 \mathrm{~B}$ variant cells in each group. A subcutaneous injection of $1 \times 10^{6}$ cells of $143 \mathrm{~B}$ or a variant was made into the right dorsal flank of each mouse. After the establishment of palpable tumors (about $\geq 5$ days), mouse body weight and external tumor volume were determined twice a week. Tumor volume was calculated using the formula $A^{2} \times B / 2$, where $A$ and $B$ represents the smallest diameter and the largest diameter, respectively. The use of the animals in the experimental protocols was reviewed and approved by the Committee of Research Center for Animal Life Science in Shiga University of Medical Science (Approved No. 2015-3-8).

In order to evaluate the xenotransplantability of $R A B 39 A$-knockdown cells, $R A B 39 A$ knockdown and the control 143B cells (shRAB and shCont) were transplanted with serial cell dilutions of $10^{6}-10^{4}$ tumor cells into each left and right backs of 6 mice each, respectively (a total of 
18 mice was used). After xenotransplanting each dilution of cells, tumor volumes and tumorigenic rates were measured in shRAB and shCont 143B tumors at 3 and 5 weeks. shRAB corresponds to $\operatorname{sh} \mathrm{RAB}(4)$ in the in vitro experiments.

After transduction with V5 or RXRB carrying vectors (labeled as V5_or RXRB_) in 143B cells, tumorigenicity for $R A B 39 A$ knockdown and the control cells (labeled as _shRAB or_shCont) were evaluated. In this case, referring to the previous data using serial cell dilution transplants, $10^{5}$ tumor cells of 2 pairs of the knockdown variants (V5 shRAB \&_shCont; and RXRB_shRAB \&_shCont) were xenotransplanted into the backs of 6 mice (a total of 12 mice was used), and tumor volumes and tumorigenic rates were measured at 3 and 5 weeks.

\section{Quantitative reverse transcription polymerase chain reaction (qRT-PCR)}

Using the acid guanidinium thiocyanate-phenolchloroform method, total RNAs were obtained from cultured cells and 13 clinical sarcoma samples, which had been collected and banked with the written informed consent of patients and after approval by the Ethics Committee of Istituto Ortopedico Rizzoli (No. 0033626), and cDNA were produced by SuperScript ${ }^{\circledR}$ VILO ${ }^{\text {TM }}$ Master Mix (Thermo). TissueScan $^{\mathrm{TM}}$ Cancer and Normal Tissue cDNA Arrays (\#CSRT103, OriGene, MD) were applied for evaluating $\sim 400$ clinically human cancer tissues, covering different malignancies of adrenal grand, breast, cervix, colon, endometrium, esophagus, kidney, liver, lung, lymphoid tissue, ovary, pancreas, prostate, stomach, testis, thyroid grand, urinary bladder and uterus (described precisely in http://www. origene.com/qPCR/Tissue-qPCR-Arrays.aspx). Quantitative PCR was performed using a TaqMan ${ }^{\circledR}$ Fast Advanced master mix and StepOnePlus ${ }^{\mathrm{TM}}$ Real-Time PCR system (Thermo). Gene expression was normalized with human beta actin (ACTB: \#4326315E) as an endogenous control in each tube, and the relative levels were calculated using the $\Delta \Delta \mathrm{Ct}$ model [40]. Probe and primer sets were prepared for human RAB39A (Hs00380029_m1), RXRB (Hs00232774_m1), CPVL (Hs01073862_m1), NUP210 (Hs00227779_m1), LHX2 (Hs00180351_m1), NCOR2 (Hs00196955_m1), UGT2B15 (Hs00870076_s1), RIIAD1 (Hs01380113_g1) and KLF4 (Hs00358836_m1); and purchased from Thermo. Each assay was repeated at least three times.

\section{Side population and stem-related surface maker analyses}

To detect cancer stem-like cells, we carried out analyses for the side population (SP) and stem-related cell surface markers, such as CD133, CD44 v5 and CXCR4. Vybrant $^{\circledR}$ DyeCycle ${ }^{\mathrm{TM}}$ Violet staining $(10 \mu \mathrm{M})$ of human stem cells enabled SP fractions to be measured by contrast with those pre-incubated with $10 \mu \mathrm{M}$ fumitremorgin $\mathrm{C}$ that inhibits ABCG2 drug transportation. The cells were washed with PBS, harvested by trypsin, and reconstituted to a final concentration of $1 \times 10^{6}$ cells $/ \mathrm{ml}$ in Live cell imaging $^{\circledR}$ reagents (Life Technologies, Thermo), together with the DyeCycle ${ }^{\mathrm{TM}}$ staining reagent for $30 \mathrm{~min}$, Then, the cells were analyzed under $405 \mathrm{~nm}$ excitation in an Attune $^{\circledR}$ Acoustic Focusing Cytometer (Thermo).

For stem-related cell surface marker analysis, the antibody for CD133 (AC133, Miltenyi Biotec, CA) or CD44 v9 (RV3, Cosmo Bio, Tokyo, Japan) was detected using Alexa Fluor $^{\circledR} 488$ goat anti-mouse or anti-rat $\operatorname{IgG}(\mathrm{H}+\mathrm{L})$, or CXCR4 (CD184, Miltenyi) pre-conjugated with phycoerythrin. Antihuman CD44 v9 (RV3) specifically detects CD44 variant isoforms (CD44 v8-10), which contribute to the defense against reactive oxygen species by promoting cystine uptake for reduced glutathione, and which drives tumor growth, chemoresistance and metastasis [41, 42]. From a preliminary analysis, CD44 v9 and CXCR4 were known to be abundant in 143B and HeLa cells, respectively, and were therefore used to evaluate each stem-like fraction; CD133 staining was too subtle to detect or to evaluate intensities in either cell type (Supplementary Figure 2A). Harvested cells ( 1 x 10 $10^{6}$ ) were stained, resuspended in $1 \mathrm{ml}$ Live cell imaging ${ }^{\circledR}$ reagents (Thermo), and gated in a forward scatter vs. side scatter, excluding debris or cell aggregations. Then, the gated cell populations were evaluated for expression of each surface maker expression under $488 \mathrm{~nm}$ excitation using an Attune ${ }^{\circledR}$ Acoustic Focusing Cytometer (Thermo).

\section{Immunoblotting}

Cells were lysed in Laemmli-SDS buffer; the solution was subjected to SDS-polyacrylamide gel electrophoresis, and then electro-transferred to membrane filters (Immuno-Blot PVDF membranes, Bio-Rad Laboratories, Richmond, CA). The filters were incubated overnight with a primary antibody of RAB39A (\#133551-AP, Proteintech, IL), RXRB (\#8715, Cell Signaling Technology, MA) or $\alpha$-tubulin (\#T9026, DM1A, Sigma-Aldrich, MO) in TBS-T containing $2 \%$ bovine serum albumin and incubated for 1 hour in horseradish peroxidase-conjugated anti-rabbit or anti-mouse secondary antibodies (Cell Signaling Technology) diluted $1: 10,000$ in TBS-T containing $2 \%$ bovine serum albumin. Immunoreactivity was detected using the Luminata Classico Western HRP substrate (Millipore Corporation) and an LAS4000 bioimager (Fujifilm, Tokyo, Japan).

\section{Evaluation for sphere viability}

Induced and reduced RAB39A variants, RAB39, V5, parental, shCont, shRAB(4) and (5), of $143 \mathrm{~B}$ and HeLa cells were seeded at 3000 cells/well into nonadhesively coated 96 well plates (Low Cell Attachment Plate PrimeSurface ${ }^{\circledR}$ MS-9096V, Sumitomo Bakelite, Tokyo, Japan), and incubated in complete DMEM-F12 
medium for sphere-forming culture, under normoxic and hypoxic $\left(1 \% \mathrm{O}_{2}\right)$ conditions. The survival of spheres was analyzed on Day 3 (72 hours after seeding) using a CellTiter-Glo ${ }^{\circledR}$ 3D Cell Viability Assay, as a luminescence value (Promega, Madison, WI).

\section{Statistical analysis}

RNA-seq data analysis was performed using Strand NGS software version 2.0 (Strand Scientific Intelligence Inc.). Other statistical analyses were performed with StatView ${ }^{\mathrm{TM}}$ version 5.0 software for Windows (SAS Institute Inc). Results are reported as means \pm standard error. One-way factorial ANOVA accompanied by Fisher's PLSD test was used to compare multiple group means. Non-parametric Mann-Whitney $U$ tests were used to compare two group means. Pearson's correlation coefficient tests were used to identify significant correlations between $R A B 39 A$ and $R X R B$ expression in tumor and normal samples. A $p$-value of $<$ 0.05 was considered statistically significant.

\section{Abbreviations}

Ras-Related Protein RAB39A (RAB39A); Retinoid X Receptor Beta (RXRB); cancer stem cell (CSC); principal component analysis (PCA); fibroblast (Fb); mesenchymal stem cell (MSC); side population (SP); quantitative reverse transcription polymerase chain reaction (qRT-PCR); vitamin $\mathrm{D}$ receptor (VDR); retinoic acid receptor (RAR).

\section{Author contributions}

TC conceived the project and designed the experiments. TC, HK, and SL conducted the experiments and analyzed the data. SA and NB also analyzed the data. TC, SA, and NB wrote the manuscript.

\section{ACKNOWLEDGMENTS}

We thank Drs. Akira Watanabe and Masahiro Nakamura (Department of Life Science Frontiers, Center for iPS Cell Research \& Application, Kyoto University) for acquisition of RNA-seq data.

\section{CONFLICTS OF INTEREST}

No potential conflicts of interest were disclosed.

\section{GRANT SUPPORT}

This work was supported by JSPS KAKENHI (Grant-in-Aid for Scientific Research, n. 25293130 to TC), AIRC (Associazione Italiana per la Ricerca sul Cancro, n. 11426 to NB), and by the financial support for Scientific Research "5 per mille 2013" (to NB).

\section{REFERENCES}

1. Bissell MJ, Radisky D. Putting tumours in context. Nat Rev Cancer. 2001; 1:46-54.

2. Marx J. Cancer biology. All in the stroma: cancer's Cosa Nostra. Science. 2008; 320:38-41.

3. Avnet S, Lemma S, Cortini M, Pellegrini P, Perut F, Zini N, Kusuzaki K, Chano T, Grisendi G, Dominici M, De Milito A, Baldini N. Altered pH gradient at the plasma membrane of osteosarcoma cells is a key mechanism of drug resistance. Oncotarget. 2016; 7:63408-63423. https:// doi.org/10.18632/oncotarget.11503.

4. Warburg O. On the origin of cancer cells. Science. 1956; 123:309-314.

5. Sedlakova O, Svastova E, Takacova M, Kopacek J, Pastorek J, Pastorekova S. Carbonic anhydrase IX, a hypoxia-induced catalytic component of the $\mathrm{pH}$ regulating machinery in tumors. Front Physiol. 2014; 4:400.

6. Chano T, Avnet S, Kusuzaki K, Bonuccelli G, Sonveaux P, Rotili D, Mai A, Baldini N. Tumour-specific metabolic adaptation to acidosis is coupled to epigenetic stability in osteosarcoma cells. Am J Cancer Res. 2016; 6:859-875.

7. Avnet S, Di Pompo G, Chano T, Errani C, Ibrahim-Hashim A, Gillies RJ, Donati DM, Baldini N. Cancer-associated mesenchymal stroma fosters the stemness of osteosarcoma cells in response to intratumoral acidosis via NF-kappaB activation. Int J Cancer. 2017; 140:1331-1345.

8. Seto S, Tsujimura K, Koide Y. Rab GTPases regulating phagosome maturation are differentially recruited to mycobacterial phagosomes. Traffic. 2011; 12:407-420.

9. Seto S, Sugaya K, Tsujimura K, Nagata T, Horii T, Koide Y. Rab39a interacts with phosphatidylinositol 3-kinase and negatively regulates autophagy induced by lipopolysaccharide stimulation in macrophages. PLoS One. 2013; 8:e83324.

10. Yu VC, Delsert C, Andersen B, Holloway JM, Devary OV, Naar AM, Kim SY, Boutin JM, Glass CK, Rosenfeld MG. RXR beta: a coregulator that enhances binding of retinoic acid, thyroid hormone, and vitamin $\mathrm{D}$ receptors to their cognate response elements. Cell. 1991; 67:1251-1266.

11. Deeb KK, Trump DL, Johnson CS. Vitamin D signalling pathways in cancer: potential for anticancer therapeutics. Nat Rev Cancer. 2007; 7:684-700.

12. O'Brien CA, Kreso A, Jamieson CH. Cancer stem cells and self-renewal. Clin Cancer Res. 2010; 16:3113-3120.

13. Bonuccelli G, Avnet S, Grisendi G, Salerno M, Granchi D, Dominici M, Kusuzaki K, Baldini N. Role of mesenchymal stem cells in osteosarcoma and metabolic reprogramming of tumor cells. Oncotarget. 2014; 5:7575-7588. https://doi. org/10.18632/oncotarget.2243.

14. Clevers H. The cancer stem cell: premises, promises and challenges. Nat Med. 2011; 17:313-319.

15. Salerno M, Avnet S, Bonuccelli G, Hosogi S, Granchi D, Baldini N. Impairment of lysosomal activity as a 
therapeutic modality targeting cancer stem cells of embryonal rhabdomyosarcoma cell line RD. PLoS One. 2014; 9:e110340.

16. Carnero A, Lleonart M. The hypoxic microenvironment: A determinant of cancer stem cell evolution. Bioessays. 2016; 38 Suppl 1:S65-74.

17. Hoftijzer HC, Liu YY, Morreau H, van Wezel T, Pereira AM, Corssmit EP, Romijn JA, Smit JW. Retinoic acid receptor and retinoid $\mathrm{X}$ receptor subtype expression for the differential diagnosis of thyroid neoplasms. Eur J Endocrinol. 2009; 160:631-638.

18. Rajkumar T, Sabitha K, Vijayalakshmi N, Shirley S, Bose MV, Gopal G, Selvaluxmy G. Identification and validation of genes involved in cervical tumourigenesis. BMC Cancer. 2011; $11: 80$.

19. Kuzmanov A, Hopfer U, Marti P, Meyer-Schaller N, Yilmaz M, Christofori G. LIM-homeobox gene 2 promotes tumor growth and metastasis by inducing autocrine and paracrine PDGF-B signaling. Mol Oncol. 2014; 8:401-416.

20. Zhou F, Gou S, Xiong J, Wu H, Wang C, Liu T. Oncogenicity of LHX2 in pancreatic ductal adenocarcinoma. Mol Biol Rep. 2014; 41:8163-8167.

21. Pardo LA, Gomez-Varela D, Major F, Sansuk K, Leurs R, Downie BR, Tietze LF, Stuhmer W. Approaches targeting $\mathrm{K}(\mathrm{V}) 10.1$ open a novel window for cancer diagnosis and therapy. Curr Med Chem. 2012; 19:675-682.

22. Park S, Lee J, Kim YH, Park J, Shin JW, Nam S. Clinical Relevance and Molecular Phenotypes in Gastric Cancer, of TP53 Mutations and Gene Expressions, in Combination With Other Gene Mutations. Sci Rep. 2016; 6:34822.

23. Gao Q, Chen X, Duan H, Wang Z, Feng J, Yang D, Song L, Zhou N, Yan X. FXYD6: a novel therapeutic target toward hepatocellular carcinoma. Protein Cell. 2014; 5:532-543.

24. Li ZM, Zhang HY, Wang YX, Wang WB. MicroRNA-137 is downregulated in human osteosarcoma and regulates cell proliferation and migration through targeting FXYD6. J Drug Target. 2016; 24:102-110.

25. Ercolak V, Paydas S, Bagir E, Ergin M, Seydaoglu G, Celik H, Yavu B, Tanriverdi K, Gunaldi M, Afsar CU, Duman BB. PRAME Expression and Its Clinical Relevance in Hodgkin's Lymphoma. Acta Haematol. 2015; 134:199-207.

26. Sun Z, Wu Z, Zhang F, Guo Q, Li L, Li K, Chen H, Zhao J, Song D, Huang Q, Li L, Xiao J. PRAME is critical for breast cancer growth and metastasis. Gene. 2016; 594:160-164.

27. Ran X, Xu X, Yang Y, She S, Yang M, Li S, Peng H, Ding $\mathrm{X}, \mathrm{Hu} \mathrm{H}, \mathrm{Hu}$ P, Zhang D, Ren H, Wu L, et al. A quantitative proteomics study on olfactomedin 4 in the development of gastric cancer. Int J Oncol. 2015; 47:1932-1944.

28. Gambarte Tudela J, Capmany A, Romao M, Quintero C, Miserey-Lenkei S, Raposo G, Goud B, Damiani MT. The late endocytic Rab39a GTPase regulates the interaction between multivesicular bodies and chlamydial inclusions. J Cell Sci. 2015; 128:3068-3081.

29. Mowers EE, Sharifi MN, Macleod KF. Autophagy in cancer metastasis. Oncogene. 2017; 36:1619-1630.
30. Mori Y, Matsui T, Omote D, Fukuda M. Small GTPase Rab39A interacts with UACA and regulates the retinoic acid-induced neurite morphology of Neuro2A cells. Biochem Biophys Res Commun. 2013; 435:113-119.

31. Kastner P, Mark M, Leid M, Gansmuller A, Chin W, Grondona JM, Decimo D, Krezel W, Dierich A, Chambon P. Abnormal spermatogenesis in RXR beta mutant mice. Genes Dev. 1996; 10:80-92.

32. Dolle P. Developmental expression of retinoic acid receptors (RARs). Nucl Recept Signal. 2009; 7:e006.

33. Vernet N, Dennefeld C, Klopfenstein M, Ruiz A, Bok D, Ghyselinck NB, Mark M. Retinoid X receptor beta (RXRB) expression in Sertoli cells controls cholesterol homeostasis and spermiation. Reproduction. 2008; 136:619-626.

34. Peng CH, Jiang YZ, Tai AS, Liu CB, Peng SC, Liao CT, Yen TC, Hsieh WP. Causal inference of gene regulation with subnetwork assembly from genetical genomics data. Nucleic Acids Res. 2014; 42:2803-2819.

35. Karami S, Andreotti G, Koutros S, Barry KH, Moore LE, Han S, Hoppin JA, Sandler DP, Lubin JH, Burdette LA, Yuenger J, Yeager M, Freeman LE, et al. Pesticide exposure and inherited variants in vitamin d pathway genes in relation to prostate cancer. Cancer Epidemiol Biomarkers Prev. 2013; 22:1557-1566.

36. Gauchotte G, Lacomme S, Brochin L, Tournier B, Cahn V, Monhoven N, Piard F, Klein M, Martinet N, Rochette-Egly C, Vignaud JM. Retinoid acid receptor expression is helpful to distinguish between adenoma and well-differentiated carcinoma in the thyroid. Virchows Arch. 2013; 462:619-632.

37. Lee SM, Lee JY, Choi JE, Lee SY, Park JY, Kim DS. Epigenetic inactivation of retinoid $\mathrm{X}$ receptor genes in non-small cell lung cancer and the relationship with clinicopathologic features. Cancer Genet Cytogenet. 2010; 197:39-45.

38. Wang SS, Menashe I, Cerhan JR, Cozen W, Severson RK, Davis S, Hutchinson A, Rothman N, Chanock SJ, Bernstein L, Hartge P, Morton LM. Variations in chromosomes 9 and $6 \mathrm{p} 21.3$ with risk of non-Hodgkin lymphoma. Cancer Epidemiol Biomarkers Prev. 2011; 20:42-49.

39. Liu RZ, Graham K, Glubrecht DD, Lai R, Mackey JR, Godbout R. A fatty acid-binding protein 7/RXRbeta pathway enhances survival and proliferation in triplenegative breast cancer. J Pathol. 2012; 228:310-321.

40. Livak KJ, Schmittgen TD. Analysis of relative gene expression data using real-time quantitative PCR and the 2(-Delta Delta C(T)) Method. Methods. 2001; 25:402-408.

41. Nagano O, Okazaki S, Saya H. Redox regulation in stemlike cancer cells by CD44 variant isoforms. Oncogene. 2013; 32:5191-5198.

42. Ishimoto $\mathrm{T}$, Nagano $\mathrm{O}$, Yae $\mathrm{T}$, Tamada M, Motohara T, Oshima H, Oshima M, Ikeda T, Asaba R, Yagi H, Masuko $\mathrm{T}$, Shimizu T, Ishikawa T, et al. CD44 variant regulates redox status in cancer cells by stabilizing the $\mathrm{xCT}$ subunit of system xc(-) and thereby promotes tumor growth. Cancer Cell. 2011; 19:387-400. 